\title{
Formulation self nano emulsifying drug delivery system glimepiride using oleic acid as oil phase
}

\section{Formulasi self nano emulsifying drug delivery system (SNEDDS) glimepirid dengan fasa minyak asam oleat}

\author{
Sani Ega Priani*, Nurrayyan, Fitrianti Darusman \\ Prodi Farmasi, Fakultas Matematika dan Ilmu Pengetahuan Alam, Universitas Islam Bandung \\ Jl.Rangga Malela No.1, Bandung 40116
}

Submitted: 23-09-2017

Reviewed: 26-10-2017

Accepted: 22-11-2017

\begin{abstract}
ABSTRAK
Glimepirid adalah obat antidiabetika golongan sulfonilurea generasi ketiga. Glimepirid memiliki kelarutan yang rendah dalam air sehingga dapat berpengaruh buruk pada disolusi dan bioavaibilitasnya. Self nanoemulsifying drug delivery systems (SNEDDS) banyak dikembangkan sebagai pembawa untuk obat yang sukar larut dalam air. Tujuan dari penelitian ini adalah untuk mengembangkan SNEDDS glimepirid yang mampu memperbaiki disolusi dan bioavaibilitasnya. SNEDDS diformulasi menggunakan asam oleat sebagai fasa minyak, tween 80 sebagai surfaktan, dan transcutol sebagai kosurfaktan karena kemampuan melarutkan zat aktif dengan baik. Sediaan SNEDDS dievaluasi meliputi penentuan $\%$ transmitan, dipersibilitas, stabilitas termodinamik, bentuk dan ukuran globul serta kecepatan disolusi. Hasil menunjukkan bahwa sediaan SNEDDS glimepirid mampu menghasilkan nanoemulsi dengan cepat dan spontan yang stabil berdasarkan uji termodinamika. Hasil transmission electron microscopy menunjukkan globul emulsi berbentuk sferis dalam ukuran nanometer. Rata-rata ukuran globul emulsi adalah $45 \mathrm{~nm}$. Sediaan SNEDDS mampu meningkatkan disolusi glimepirid secara signifikan dibandingkan zat aktif murninya.
\end{abstract}

Kata kunci: SNEDDS, glimepirid, asam oleat, disolusi

\begin{abstract}
Glimepiride is a third generation sulphonylurea antidiabetic drug. Glimepiride is poorly water soluble drug that may cause poor dissolution and unpredicted bioavailability. Self nanoemulsifying drug delivery systems (SNEDDS) have become a popular formulation option as nanocarriers for poorly water-soluble drugs. The objective of this research was to develop SNEDDS formulation of glimepiride to improve oral dissolution and bioavailability. Glimepiride SNEDDS was formulated using oleic acid as oil phase, tween 80 as surfactant, and transcutol as co-surfactant due to their higher solubilization effect. The formulated SNEDDS were evaluated for $\%$ transmittance, dispersibility, thermodynamic stability, dissolution, globule size and morphology analysis. The results showed that the glimepiride SNEDDS was rapidly formed clear emulsion and stabile based on thermodynamic test.
\end{abstract}

\footnotetext{
Penulis korespondesi:

Sani Ega Priani

Farmasi, Fakultas Matematika dan Ilmu Pengetahuan Alam, Universitas Islam Bandung

Jln. Rangga Malela No.1 Bandung

Email:egapriani@gmail.com
} 
Transmission electron microscopy demonstrated the spherical droplets morphology in nanometer range. The globule average diameter size was $45 \mathrm{~nm}$. The SNEDDS formulation significantly increase dissolution of glimepiride compared with pure drug.

Keywords: SNEDDS, glimepiride, oleic acid, dissolution

\section{PENDAHULUAN}

Glimepirid merupakan obat anti diabetika oral yang bekerja merangsang sekresi insulin dengan mengikat reseptor sulfonilurea pada membran plasma sel beta pankreas. Glimepirid merupakan obat golongan BCS (Biopharmaceutical Classification System) kelas II karena memiliki kelarutan yang rendah dalam air namun memiliki permeabilitas yang tinggi (Shah et al., 2013). Sifatnya yang sukar larut dalam air, akan menimbulkan masalah pada disolusi dan absorpsinya di saluran cerna. Oleh karena itu, perlu dilakukan pengembangan formula yang mampu meningkatkan disolusi dari glimepirid. Salah satu bentuk sediaan yang diketahui mampu meningkatakn disolusi senyawa yang sukar larut dalam air adalah Self-Nanoemulsifying Drug Delivery System (SNEDDS).

SNEDDS merupakan sistem penghantaran obat multikomponen yang terdiri dari minyak, surfaktan, dan kosurfaktan yang dengan pengadukan sedang, dapat membentuk nanoemulsi minyak dalam air (ukuran globul $<100 \mathrm{~nm}$ ) saat kontak dengan media air misalnya dengan cairan gastrointestinal (Seema and Kuma., 2014). Globul berukuran nano tersebut menyebabkan terjadinya pelepasan dan absorpsi zat aktif dengan cepat di saluran cerna. Oleh karena itu, formulasi sediaan SNEDDS diketahui mampu memperbaiki disolusi dan bioavaibilitas dari zat yang bersifat lipofil atau sukar larut dalam air (Soni et al., 2014; Wang et al., 2015). Dibandingkan dengan sediaan nanoemulsi konvensional, kelebihan dari sediaan SNEDDS adalah meningkatnya stabilitas fisika dan kimia dari sediaan karena diformulasi tanpa air dan sediaan SNEDDS dapat dikemas dalam sediaan dosis tunggal menggunakan kapsul keras dan kapsul lunak (Shahba et al., 2012).

Pada penelitian ini dilakukan pembuatan sediaan SNEDDS dengan kandungan zat aktif glimepirid untuk meningkatkan disolusi glimepirid dalam saluran gastrointestinal, sehingga pada akhirnya diharapkan mampu meningkatkan bioavaibilitasnya. Sediaan SNEDDS diformulasi menggunakan berbagai formula dengan variasi konsentrasi minyak, surfaktan dan kosurfakatan dan kemudian dievaluasi untuk mengetahui karakteristik fisika dan kimianya.

\section{Metode Penelitian \\ Alat dan Bahan}

Alat yang digunakan pada penelitian ini adalah spektrofotometer UV (Shimadzu UV mini1240), Particle Size Analyzer (Beckman Coulter LS 13 320), Transmission Electron Microscopy (JEOL JEM 1400), vortex (Thermo Scientific), alat uji disolusi, sonikator (Bransonic CPX2800H-E), magnetic stirrer (Termolyne S131120-33Q), stopwatch (Digitec).

Bahan yang digunakan pada penelitian ini adalah glimepirid (PT. Kimia Farma, Tbk.), isopropil miristat, minyak biji bunga matahari, minyak zaitun, asam oleat, tween 80 , cremophor $\mathrm{RH} 40$, propilenglikol, PEG 400, dan transcutol.

\section{Cara Kerja}

\section{Uji kelarutan glimepirid}

Dilakukan uji kelarutan glimepirid dalam berbagai pembawa (minyak, surfaktan dan kosurfaktan). Dibuat berbagai perbandingan glimepirid dan pembawa (dalam tabung terpisah) kemudian dilihat kelarutannya setelah diaduk menggunakan vortex selama 5 menit. Perbandingan yang digunakan adalah $1: 1 ; 1: 2 ; 1: 3 ; 1: 4 ; 1: 5 ; 1: 6 ; 1: 7 ; 1: 8$. Pengujian dihentikan bila sudah diketahui perbandingan yang mampu melarutkan glimepirid dengan sempurna (Chavda et al., 2013).

\section{Optimasi konsentrasi minyak, surfaktan, dan kosurfaktan dalam formula SNEDDS}

Dibuat 9 formula SNEDDS dengan perbandingan minyak dan (surfaktan+kosurfaktan) 1:9; 1:8 dan $1: 7$ serta perbandingan surfaktan: kosurfaktan $3: 1 ; 2: 1 ; 3: 2$. SNEDDS dibuat dengan cara 
mencampurkan fase minyak, surfaktan dan kosurfaktan dan diaduk menggunakan vortex sampai homogen setelah dipanaskan pada suhu $40^{\circ} \mathrm{C}$. Terhadap formula hasil optimasi dilakukan evaluasi meliputi pengukuran nilai persen transmitan dan pengujian dispersibilitas (Shah et al., 2013).

\section{Pembuatan formula SNEDDS glimepirid}

Setelah diperoleh formula optimum SNEDDS, dibuat formula akhir SNEDDS yang mengandung glimepirid $1 \mathrm{mg} / \mathrm{mL}$. SNEDDS dibuat dengan mencampurkan minyak (asam oleat), surfaktan (tween 80) dan kosurfaktan (trancutol) terpilih. Campuran dipanaskan pada suhu $40^{\circ} \mathrm{C}$, lalu ditambahkan glimepirid dan divortex sampai homogen kemudian dilanjutkan dengan sonikasi selama 15 menit (Shah et al., 2013; Wadhwa et al., 2015).

\section{Evaluasi formula SNEDDS}

Terhadap formula SNEDDS glimepirid dilakukan evaluasi meliputi:.

\section{Pengukuran persen transmitan}

Sebanyak $1 \mathrm{~mL}$ formula SNEDDS masing-masing ditambahkan dengan $100 \mathrm{~mL}$ aquades lalu dikocok hingga homogen. Selanjutnya dilakukan pengukuran persen transmitan pada panjang gelombang $650 \mathrm{~nm}$ menggunakan aquades sebagai blangko (Senapati et al., 2016).

\section{Pengujian dispersibilitas}

Pengujian dispersibilitas dilakukan dengan menggunakan alat uji disolusi tipe II. Sebanyak 1 $\mathrm{mL}$ formula SNEDDS masing-masing ditambahkan ke dalam $500 \mathrm{~mL}$ aquades pada suhu $37 \pm 0.5{ }^{\circ} \mathrm{C}$ dengan kecepatan $50 \mathrm{rpm}$. Formulasi SNEDDS dinilai dari tampilan secara visual sesuai dengan tingkat emulsifikasi, dievaluasi menggunakan sistem penilaian pada Tabel I (Nasr et al., 2016).

Tabel I. Interpretasi hasil pengujian dispersibilitas

\begin{tabular}{cl}
\hline Grade & \multicolumn{1}{c}{ Keterangan } \\
\hline $\mathrm{A}$ & $\begin{array}{l}\text { Cepat membentuk nanoemulsi (dalam 1 menit), memiliki penampilan yang jernih } \\
\text { Cepat membentuk nanoemulsi, emulsi sedikit kurang jernih, memiliki } \\
\text { penampilan putih kebiruan }\end{array}$ \\
$\mathrm{B}$ & $\begin{array}{l}\text { Emulsi putih susu yang terbentuk dalam waktu 2 menit } \\
\text { Kusam, emulsi putih keabu abuan dengan penampilan sedikit berminyak yang }\end{array}$ \\
$\mathrm{C}$ & $\begin{array}{l}\text { lambat membentuk emulsi (lebih dari 2 menit) } \\
\mathrm{D}\end{array}$ \\
$\mathrm{E}$ & Formulasi menunjukkan sedikit teremulsifikasi dengan ukuran globul minyak \\
&
\end{tabular}

\section{Pengujian robustness}

Sebanyak $1 \mathrm{~mL}$ formula SNEDDS masing-masing dimasukkan dalam $100 \mathrm{~mL}$ media aquades, $\mathrm{HCl} 0,1 \mathrm{~N}$ dan dapar fosfat $\mathrm{pH}$ 6,8, lalu dilakukan pengadukan menggunakan magnetic stirrer dengan kecepatan $100 \mathrm{rpm}$ pada suhu $37^{\circ} \mathrm{C}$. Selanjutnya dilakukan penyimpanan pada suhu kamar selama 24 jam. Kemudian diamati secara visual setiap tanda-tanda pemisahan fase (Nasr et al., 2016).

\section{Pengujian termodinamika}

Terdapat 3 macam pengujian termodinamika, yaitu heating cooling cycle, sentrifuga dan freeze thaw cycle.

\section{Heating cooling cycle}

Pengujian dilakukan pada formula SNEDDS dengan 6 siklus antara suhu lemari pendingin $4^{\circ} \mathrm{C}$ dan $45^{\circ} \mathrm{C}$ dengan penyimpanan pada setiap suhu tidak kurang dari 48 jam (Vilas, 2014).

\section{Sentrifuga}

Formulasi SNEDDS disentrifugasi dengan kecepatan 2500 rpm selama 40 menit (Vilas, 2014).

\section{Freeze thaw cycle}

Formula SNEDDS diuji menggunakan freeze thaw cycle pada suhu $-21^{\circ} \mathrm{C}$ dan $25^{\circ} \mathrm{C}$ dengan penyimpanan pada setiap suhu tidak kurang dari 48 jam (Vilas, 2014). 


\section{Penentuan ukuran partikel/globul}

Penentuan ukuran partikel dilakukan menggunakan alat particle size analyzer (PSA). Sebanyak $100 \mu \mathrm{L}$ formula SNEDDS dilarutkan kedalam $100 \mathrm{~mL}$ aquades dan diameter globul diukur menggunakan alat PSA (Zhao et al., 2010).

\section{Pengujian visualisasi morfologi nanoemulsi}

Untuk mengetahui morfologi dari nanoemulsi secara visual, dilakukan pengujian dengan menggunakan transmission electron microscopy (TEM). Formula SNEDDS dilarutkan dalam aqua p.i dengan perbandingan 1:1000, lalu diamati morfologi nya menggunakan TEM (Salunkhe et al., 2014; Kaur et al., 2013).

\section{Penetapan kadar}

SNEDDS glimepirid ditimbang sebanyak $10 \mathrm{mg}$ lalu dilarutkan kedalam dapar fosfat $\mathrm{pH}$ 7,4. Selanjutnya larutan disonikasi selama 10 menit lalu disaring. Absorbansi filtrat diukur menggunakan spektrofotometer UV pada panjang gelombang maksimum (Reddy et al., 2015). Sebelumnya dilakukan penentuan panjang gelombang maksimum dan dibuat kurva kalibrasi glimepirid pada konsentrasi 6, 8, 10, 12 dan $14 \mathrm{ppm}$.

\section{Pengujian disolusi}

Dilakukan uji disolusi terhadap formula SNEDDS glimepirid dan glimepirid murni dengan menggunakan alat uji disolusi tipe II dengan kecepatan putaran $50 \mathrm{rpm}$ dalam $900 \mathrm{~mL}$ dapar fosfat $\mathrm{pH}$ 7,4 pada suhu $37^{\circ} \mathrm{C} .5 \mathrm{~mL}$ aliquot diambil pada waktu 5, 10, 15, dan 30 menit. Selanjutnya konsentrasi glimepirid diukur menggunakan spektrofotometer UV pada panjang gelombang maksimumnya (Shah et al., 2013; Reddy et al., 2015). Dilakukan juga pengujian uji disolusi terhadap basis SNEDDS (tanpa glimepirid) dengan kondisi uji yang sama. Sampel yang diperoleh pada uji terhadap basis pada setiap interval waktu, digunakan sebagai blanko pada pengujian spektrofotometri UV sampel uji disolusi SNEDDS Glimpirid. Hal tersebut dilakukan untuk menghilangkan pengaruh absorbansi yang ditimbulkan basis.

\section{HASIL DAN PEMBAHASAN}

\section{Uji kelarutan glimeprid}

Dalam formulasi SNEDDS, kelarutan zat aktif dalam pembawa (minyak, surfaktan dan kosurfaktan) akan mempengaruhi karakteristik sediaan akhir yang dihasilkan. Semakin baik kelarutan zat aktif dalam pembawa akan semakin banyak jumlah zat aktif yang dapat dicampurkan ke dalam sediaan SNEDDS. Hasil pengujian kelarutan glimeprid dalam berbagai pembawa ditampilkan pada Tabel II. Berdasarkan hasil pengujian, pembawa yang mampu melarutkan glimepirid paling baik yaitu asam oleat sebagai fase minyak, tween 80 sebagai surfaktan dan transcutol sebagai kosurfaktan.

Tabel II. Hasil uji kelarutan glimepirid

\begin{tabular}{ccc}
\hline Jenis & Bahan & $\begin{array}{c}\text { Kelarutan Glimepirid (mg) } \\
\text { dalam pembawa (mL) }\end{array}$ \\
\hline Minyak & Minyak Zaitun & $1: 4$ \\
& Minyak Biji Bunga Matahari & $1: 3$ \\
& Isopropil Miristat & $1: 3$ \\
Surfaktan & Asam Oleat & $1: 1$ \\
& Tween 80 & $1: 4$ \\
Kosurfaktan & Cremophor RH 40 & $1: 7$ \\
& Transcutol & $1: 1$ \\
& PEG 400 & $1: 3$ \\
& Propilenglikol & $1: 3$ \\
\hline
\end{tabular}




\section{Optimasi konsentrasi minyak, surfaktan, dan kosurfaktan dalam formula SNEDDS}

Untuk mendapatkan formula SNEDDS optimum di buat 9 variasi formula. Terhadap formula yang dihasilkan dilakukan uji persen transmitan dan uji dispersibilitas untuk mengetahui formula terbaik. Pengujian persen transmitan dilakukan untuk melihat kejernihan sediaan setelah dilakukan pengenceran 1 : 100 (Senapati et al., 2016). Formula SNEDDS yang baik adalah formula yang memiliki nilai persen transmitan mendekati $100 \%$ karena dengan begitu diperkirakan globul yang terbentuk telah mencapai ukuran nanometer (Amrutkar et al.,2014). Dari hasil pengujian dipilih 4 formula terbaik yakni F2, F3, F4 dan F5 yang memiliki nilai persen transmitan >95\% (Tabel III). Nilai persen transmitan >95\% mengindikasikan pembentukan emulsi yang jernih (Reddy et al., 2016).

Tabel III. Hasil pengujian persen transmitan pada optimasi formula

\begin{tabular}{cccc}
\hline Formula & Perbandingan M : (S+K) & Perbandingan $(\mathbf{S : K})$ & \% Transmitan \\
\hline F1 & $1: 9$ & $3: 2$ & $94,0 \pm 0,265$ \\
F2 & $1: 9$ & $2: 1$ & $98,7 \pm 0,700$ \\
F3 & $1: 9$ & $3: 1$ & $95,7 \pm 2,797$ \\
F4 & $1: 8$ & $3: 2$ & $96,8 \pm 0,100$ \\
F5 & $1: 8$ & $2: 1$ & $97,6 \pm 0,700$ \\
F6 & $1: 8$ & $3: 1$ & $93,0 \pm 2,170$ \\
F7 & $1: 7$ & $3: 2$ & $88,5 \pm 0,751$ \\
F8 & $1: 7$ & $2: 1$ & $81,1 \pm 1,677$ \\
F9 & $1: 7$ & $3: 1$ & $56,5 \pm 1,986$ \\
\hline
\end{tabular}

Selanjutnya terhadap ke-4 formula, dilakukan pengujian dispersibilitas. Uji dispersibilitas dilakukan untuk mengukur kecepatan terbentuknya nanoemulsi, dan melihat secara visual tingkat emulsifikasi yang terjadi. Pada pengujian ini ditetapkan penilaian grade, dimana pembentukan emulsi grade A dan B menunjukkan keberhasilan terbentuknya nanoemulsi pada formula (Nasr et al., 2016). Hasil uji menunjukkan keempat formula memenuhi persyaratan uji dispersibilitas (Tabel IV). Hal tersebut ditunjukkan dengan waktu dispersibilitas yang <1 menit dan terbentuk larutan yang jernih yang mengindikasikan pembentukan nanoemulsi.

Tabel IV. Hasil uji dispersibilitas pada optimasi fomula

\begin{tabular}{cccc}
\hline Formula & Waktu Dispersibiltas (Detik) & Kejernihan & Grade \\
\hline F2 & $20,78 \pm 1,17$ & Jernih & $\mathrm{A}$ \\
F3 & $14,26 \pm 1,00$ & Jernih & $\mathrm{A}$ \\
F4 & $15,25 \pm 1,26$ & Jernih & $\mathrm{A}$ \\
F5 & $24,33 \pm 1,61$ & Jernih & $\mathrm{A}$ \\
\hline
\end{tabular}

\section{Optimasi formula SNEDDS glimepirid}

Kedalam 4 formula SNEDDS optimum dilakukan penambahan glimepirid dengan konsentrasi 1 $\mathrm{mg} / \mathrm{mL}$. Untuk skrining awal keberhasilan SNEDDS dilakukan pengujian persen transmitan terhadap formula SNEDDS glimepirid (Tabel V). Dari hasil pengujian diketahui bahwa formula F3A memiliki nilai persen transmitan terbaik dan mengindikasikan kejernihan sistem emulsi karena nilai persen transmitannya $>95 \%$ (Reddy et al., 2016). Hasil uji dispersibilitas terhadap formula F3A menunjukkan waktu dispersibilitas 19,01 $\pm 1,40$ detik yang memenuhi kriteria emulsifikasi grade A. 
Tabel V. Hasil pengujian persen transmitan optimasi SNEDDS glimepirid

\begin{tabular}{cc}
\hline Formula & \% Transmitan \\
\hline F2A & $62,10 \pm 0,569$ \\
F3A & $95,77 \pm 0,473$ \\
F4A & $92,5 \pm 0,200$ \\
F5A & $82,9 \pm 1,328$ \\
\hline
\end{tabular}

\section{Evaluasi sediaan SNEDDS glimepirid}

Terhadap sediaan SNEDDS F3A dilakukan evaluasi lebih lanjut untuk menentukan karakterisasi fisika dan kimia sediaan SNEDDS yang dihasilkan. Hasil uji dapat dilihat pada Tabel VI.

Tabel VI. Hasil evaluasi SNEDDS glimepirid 1 mg/mL (Fomula F3A)

\begin{tabular}{ccc}
\hline \multicolumn{2}{c}{ Jenis Pengujian } & Hasil \\
\hline Waktu dispersibilitas dan & Aquadest & 32,8 detik (Stabil) \\
Robustness & Dapar Fosfat $\mathrm{pH} \mathrm{6,8}$ & 21,01 detik (Stabil) \\
& HCl 0,1 N & 27,23 detik (Stabil) \\
Stabilitas Termodinamika & Heating cooling & Stabil \\
& Sentrifugasi & Stabil \\
& Freeze thaw & Stabil \\
& Kadar zat aktif & $100,64 \pm 0,108 \%$ \\
Rata rata ukuran globul & $45 \mathrm{~nm}$ \\
\hline
\end{tabular}

Sediaan SNEDDS glimepirid yang dihasilkan membentuk caitan kental yang bening dengan warna kekuningan (Gambar 1). Dari hasil evaluasi sediaan terlihat bahwa sediaan SNEDDS memenuhi persyaratan dilihat dari aspek kemampuan terdispersi spontan membentuk sistem emulsi yang bening dan aspek stabilitas termodinamik. Pengujian robustness dan dipersibilitas pada tiga jenis pelarut menggambarkan bahwa sediaan mampu membentuk emulsi spontan baik pada lingkungan $\mathrm{pH}$ asam yang mewakili kondisi lambung atau pada dapar fosfat 6,8 yang mewakili kondisi usus halus.

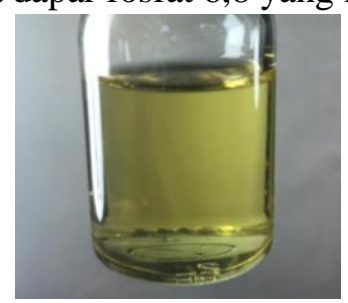

\section{Gambar 1. SNEDDS Glimepirid}

Hasil penentuan ukuran globul menggunakan alat particle size analyzer menunjukkan bahwa rata-rata ukuran globul $45 \mathrm{~nm}$ (Gambar 2). Hal tersebut menunjukkan bahwa sediaan yang terbentuk memenuhi persyaratan SNEDDS karena mampu membentuk nanoemulsi secara spontan dengan ukuran globul $<100 \mathrm{~nm}$ (Seema and Kuma, 2014). Selanjutnya dilakukan pengujian untuk melihat morfologi globul nanoemulsi yang terbentuk menggunakan transmission electron microscopy (TEM). Hasilnya memperlihatkan globul-globul berukuran nano dengan bentuk sferis (Gambar 3). 


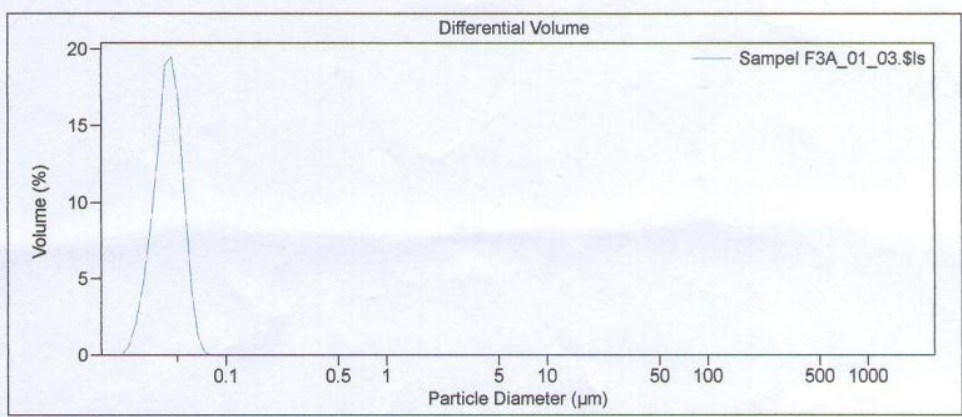

Gambar 2. Hasil pengujian ukuran globul SNEDDS menggunakan alat PSA

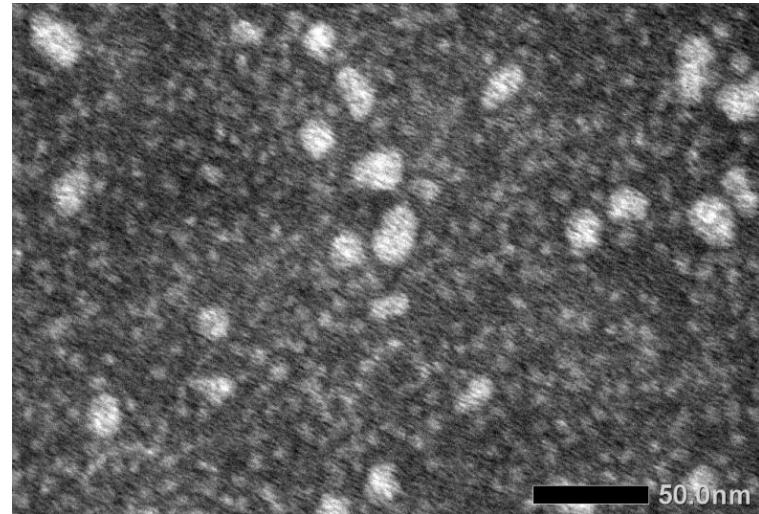

Gambar 3. Hasil TEM SNEDDS glimepirid

Untuk melihat pengaruh sediaan SNEDDS terhadap disolusi glimepririd dilakukan uji disolusi secara in vitro dan dibandingkan dengan kecepatan disolusi zat aktif murninya. Profil laju disolusi pada sediaan SNEDDS glimepirid menunjukkan laju disolusi yang jauh lebih tinggi dibandingkan laju disolusi glimepirid murni (Gambar 4). Dalam bentuk sediaan SNEDDS, glimepirid sudah terdisolusi sempurna pada waktu 10 menit. Hal ini menunjukkan bahwa pembuatan sediaan SNEDDS dapat memperbaiki laju disolusi glimepirid, dikarenakan terdapat fase minyak yang dapat melarutkan glimepirid lebih baik, juga terdapat surfaktan dan kosurfaktan yang membantu peningkatan kelarutan dari glimepirid. Terbentuknya globul berukuran nano disaluran cerna memungkinkan pelepasan zat yang lebih baik dan mampu memperbaiki disolusinya (Soni et al., 2014).

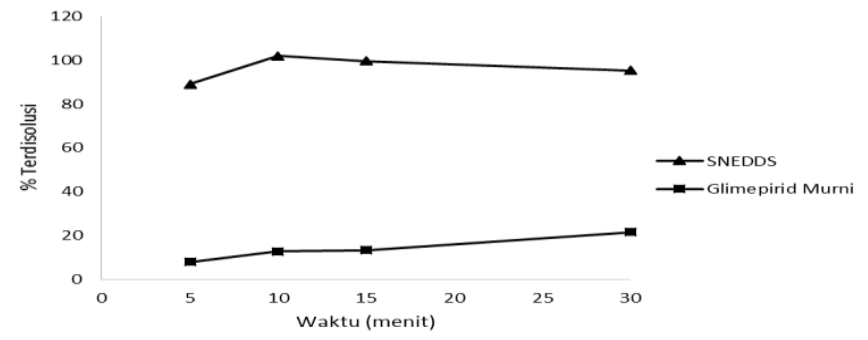

Gambar 4. Hasil uji disolusi glimepirid 


\section{KESIMPULAN}

Telah berhasil dibuat SNEDDS glimepirid $1 \mathrm{mg} / \mathrm{mL}$ dengan menggunakan fasa minyak asam oleat, surfaktan tween 80 dan kosurfaktan transcutol dengan perbandingan minyak : (surfaktan \& kosurfaktan) 1:9 dan perbandingan surfaktan : kosurfaktan 3:1. SNEDDS yang terbentuk memenuhi persyaratan uji persen transmitan, dispersibilitas, robustness, dan stabilitas termodinamika. SNEDDS glimepirid memenuhi kriteria sediaan nano dengan ukuran globul rata-rata $45 \mathrm{~nm}$ dan berbentuk sferis. Sediaan SNEDDS terbukti dapat meningkatkan disolusi dari zat aktif glimepirid dibandingkan dengan glimepirid murni.

\section{DAFTAR PUSTAKA}

Amrutkar, C., Salunkhe K., Chaudhari S., 2014, Study on Self Nano Emulsifying Drug Delivery System of Poorly Water Soluble Drug Rosuvastatin Calcium, World Journal of Pharmaceutical Research, 3(4), 2137-2151.

Chavda, H., Patel J., Chavda G., Dave S., Patel A., Patel C., 2013, Self-Nanoemulsifying Powder of Isotretinoin: Preparation and Characterization, Journal of Powder Technology, 2013: 1-9.

Kaur, G., Chandel P., Harikumar S.L, 2013, Formulation Development Of Self Nanoemulsifying Drug Delivery System (Snedds) Of Celecoxib For Improvement Of Oral Bioavailability, Pharmacophore, 4(4): 120-133.

Nasr, A., Gardouh A., Ghorab M., 2016, Effect of Oils, Surfactants and Cosurfactants on Phase Behavior and Physicochemical Properties of Self- Nanoemulsifying Drug Delivery System (SNEDDS) for Irbesartan and Olmesartan, International Journal of Applied Pharmaceutics, 8(1): $1-9$.

Reddy, M.S., Sowjanya N., 2015, Formulation and in-vitro Characterization of Solid Self Nanoemulsifying Drug Delivery System (s-SNEDDS) of Simvastatin, Journal of Pharmaceutical and Science, 7(1): 40-48.

Reddy, M.S., G. Harish, Md. Fazal U., 2016, Formulation and in-vitro characterization S-SNEDDS of Rilpivirine, Int J Pharm Sci Res, 7(7): 3117-3129.

Salunkhe, S.S., Thorat J.D., Bhatia M.S., Bhatia N.M., Choudhari P.B., 2014, Formulation, Development and Evaluation of Ibuprofen Loaded NanoemulsionPrepared by Nanoprecipitation Technique: Use of Factorial Design Approach as a Tool of Optimization Methodology, Journal of Pharmaceutical Investigation, 44(4): 273-290.

Seema, G., Kuma, S.A., 2014, Self Nanoemulsifying Drug Delivery System- A Noval Approach For Improving Bioavailability, Journal of Drug Delivery \& Therapeutics, 6: 2191-2194.

Senapati, P.C., Sahoo S.K., Sahu A.N., 2016, Mixed Surfactant Based (SNEDDS) SelfNanoemulsifying Drug Delivery System Presentig Efavirenz for Enhancement of Oral Bioavaibility, Biomedicine \& Pharmacoterapy, 80: 42-51

Shahba,A.W., Kazi M., Fars K.A., 2012, Novel Self-Nanoemulsifying Drug Delivery Systems (SNEDDS) for Oral Delivery of Cinnarizine: Design, Optimization, and In-Vitro Assessment, AAPS PharmSciTech, 13(3): 967-977.

Shah, S.E., Parikh R.H.., Chavda J.R., Sheth N.R., 2013, Self-Nanoemulsifying Drug Delivery System of Glimepiride: Design, Development and Optimization, J Pharm Sci and Tech, 67(3): 201-213.

Soni, G.C., Prajapati S.K., Chaudhri, N., 2014, Self Nanoemulsion: Advance Form Of Drug Delivery System, World journal of Pharmacy and Pharmaceutical Sciences, 3(10): 410-436.

Vilas, P.C., 2014, Preparation and In Vitro Evaluation of Self-Nanoemulsifying Drug Delivery System (SNEDDS) Containing Clopidogrel, Int. J. Pharm. Sci. Rev. Res, 25(1): 10-15.

Wadhwa, J., Asthana A., Shilakari G., Chopra A.K., Singh R., 2015, Development and Evaluation of Nanoemulsifying Preconcentrate of Curcumin for Colon Delivery, The Scientific World Journal, 2015:1-15.

Wang, H., Li Q., Deng W., Siaw E.O., Wang Q., Wang S., Cao X., Xu X., Yu J., 2015, SelfNanoemulsifying Drug Delivery System of Trans-Cinnamic Acid: Formulation Development 
and Pharmacodynamic Evaluation in Alloxan Induced Type 2 Diabetic Rat Model, Drug Development Research, 76 (2): 82-93.

Zhao, Y., Wang C., Chow A.H.L., Ren K., Gong T., Zhang Z., Zhenga Y. , 2010, Selfnanoemulsifying drug delivery system (SNEDDS) for oral delivery of Zedoary essential oil: Formulation and bioavailability studies, International Journal of Pharmaceutics, 383: 170-177. 
